\title{
Look back to assure a better future
}

\author{
Stephen Porter, ${ }^{* 1}$ Jair Carneiro Leão, ${ }^{2}$ Daniel Cohen Goldemberg ${ }^{3}$ and Stefano Fedele ${ }^{1,4}$
}

The BDJ Upfront section includes editorials, letters, news, book reviews and interviews. Please direct your correspondence to the News Editor,

Kate Quinlan at k.quinlan@nature.com. Press releases or articles may be edited, and should include a colour photograph if possible.

$\mathrm{M}$ any individuals have experienced illness, pain and upset as a consequence of lockdowns, social distancing policies and/or the reconfiguration of clinical services. It is hoped that the present COVID-19 pandemic will settle although further, potentially significant outbreaks across the globe are anticipated - or arising. There may be insufficient time, and probably resources, to develop or instigate policies that may mitigate against future needs but now may be the time to consider the very many implications of this first COVID-19 pandemic for immediate and long term future oral healthcare. consumption ${ }^{5}$ may have created a burden of facial injuries that is presently completely unknown to healthcare professionals or reflected within the rise in injuries due to falls/trips within homes or the reports of facial injury due to deliberate self-harm. ${ }^{6}$

The present examples are the tip of an iceberg of possible health burden. There is the potential for repetition with any further COVID-19 outbreaks but there may be lessons to learn (for example triage, training and timetabling) that may help - even in the absence of any further pandemic. We urge leaders of the different specialties of oral healthcare in the UK and around the globe to

\section{'We urge leaders of the different specialties of oral healthcare in the UK and around the globe to undertake meaningful lookback analyses'}

\section{Undoubtedly lookbacks should focus} upon strategies to enhance the delivery of acute care of plaque-induced dental disease as these are the dominant oral disorders of children and adults in the UK and across the globe. Nevertheless each specialty area will have had specific challenges that may warrant - or provide - solutions. For example, consideration must be given to the probable reduction in the identification and treatment of oral malignancies, ${ }^{1}$ any worsening of immunologically-mediated disease ${ }^{2}$ and any increases in numbers of individuals with facial pain secondary to psychological distress. ${ }^{3}$ Within oral and maxillofacial surgery it is probable that injuries due to contact sports, road traffic accidents or violence have fallen but, as highlighted by Coulthard and colleagues, injuries due to domestic violence may rise. ${ }^{4}$ Of concern, the combination of psychological stress due to prolonged social isolation and alcohol undertake meaningful lookback analyses that will inform the roadmap for oral healthcare in the twenty-first century. There will be limited, if any, funding opportunities for appropriate analyses hence proposed studies must be methodologically sound to identify where, even simple, change will positively impact upon oral healthcare.

Aligned to this we propose that future public health strategies recognise the worth of primary dental healthcare providers to monitor COVID-19 community infection. The great majority of dentistry is delivered in readily accessible practices by staff skilled in the examination of the mouth and potentially the upper airway. If practices are unable to deliver the usual care (for example due to regulatory concerns of increased transmission due to aerosol generating procedures containing COVID-19) it is highly likely that they would be able and willing to become local test centres to monitor outbreaks - perhaps also using the facilities of community pharmacies - to assure rapid identification of pockets of new infection. ${ }^{7}$

Change requires strong vision, leadership, willpower, resources and pragmatism. It is our view that with an appropriate well-resourced roadmap, informed by the solutions of the recent past, all oral healthcare providers, whether generalists or specialists, have much to contribute to lessen the burden of any future, or indeed continued, outbreaks of COVID-19 infection. ${ }^{8}$

\section{References}

1. Lai AG, Pasea L, Banerjee A et al. Estimating excess mortality in people with cancer and multimorbidity in the COVID-19 emergency. medRxiv 2020; 2020.05.27.20083287.

2. Wollina U. Challenges of Covid-19 Pandemic for Dermatology. Dermatol Ther 2020; $1-5$.

3. Smith L, Jacob L, Yakkundi A et al. Correlates of symptoms of anxiety and depression and mental wellbeing associated with COVID-19: a cross-sectional study of UK-based respondents. Psychiatry Res 2020; 291. doi:10.1016/j.psychres.2020.113138.

4. Coulthard P, Hutchison I, Bell JA, Coulthard ID, Kennedy H. COVID-19, domestic violence and abuse, and urgent dental and oral and maxillofacial surgery care. Br Dent $\lrcorner$ 2020; 228: 923-926.

5. Finlay I, Gilmore I. Covid-19 and alcohol-a dangerous cocktail. BMJ 2020; 369: m1987.

6. Blackhall KK, Downie IP, Ramchandani P et al. Provision of Emergency Maxillofacial Service During the COVID-19 Pandemic: A Collaborative Five Centre UK Study. Br J Ora Maxillofac Surg 2020. doi:10.1016/j.bjoms.2020.05.020.

7. Li R, Pei S, Chen B et al. Substantial undocumented infection facilitates the rapid dissemination of novel coronavirus (SARS-CoV2). Science 2020; 493: 489-493.

8. The Academy of Medical Sciences. Preparing for a challenging winter 2020/21. https://acmedsci.ac.uk/ file-download/51353957 (accessed July 2020).

https://doi.org/ 10.1038/s41415-020-1925-8

${ }^{1}$ UCL Eastman Dental Institute, London UK. ${ }^{2}$ Federal University of Pernambuco (UFPE), Recife, Brazil ${ }^{3}$ National Cancer Institute of Brazil (INCA), Rio de Janeiro, Brazil; ${ }^{4}$ UCLH/UCL NIHR Biomedical Research Centre, London, UK

*Corresponding author: Institute Director and Professor of Oral Medicine UCL Eastman Dental Institute, 256 Grays Inn Road, London WC1X 8LD

Email: s.porter@ucl.ac.uk 